\title{
A Novel Method to Valorize Frequency Support Procurement by Wind Power Plants
}

\author{
A. B. Attya, and Jose Luis Dominguez-Garcia
}

\begin{abstract}
The provision of frequency support by renewable power is a key challenge to allow higher penetration of renewables. While the research efforts focus on proposing new control methods and market structures to realize and facilitate the provision of frequency services by wind power, less attention is given to financial compensation of proper responses. This paper proposes a comprehensive method to evaluate the net payments to participating wind power plants, including a penalty factor for responses that do not comply with grid codes and market bids. This method integrates frequency data and dynamic response of wind power assets during the events, to evaluate the compliance level under a certain grid code, and calculates the corresponding net payment. The paper demonstrates the method by integrating the worst frequency event in each month from the real recorded data of UK National grid frequency response in 2016. The results obtained show clear diversities between the three examined support methods with clear influence of the incident wind speed. Kinetic energy extraction support method shows a little merit at high wind speeds, while pitch deloading method performs better at the majority of the examined case studies.
\end{abstract}

Index Terms - Wind power plants, ancillary services, frequency stability, grid codes, reserve markets.

\section{NOMENCLATURE}

$\triangle \mathrm{E} \quad$ Energy support during frequency event [MWH]

$\Delta \mathrm{P}_{5}, \Delta \mathrm{P}_{30}$ Average power support within 5s and 30s [MW]

$\triangle P_{a} \quad$ Actual power support [MW]

$A_{\delta} \quad$ Tolerance factor [-]

$\mathrm{CF} \quad$ Capacity factor [-]

$\mathrm{C}_{\mathrm{P}}, \mathrm{C}_{\mathrm{E}} \quad$ Power and energy prices [€/MW, $\left.€ / \mathrm{MWH}\right]$

$\mathrm{D}_{\mathrm{F}} \quad$ Deloading ratio [-]

$\mathrm{f}_{\text {low }} \quad$ Frequency violation threshold $[\mathrm{Hz}]$

$\mathrm{f}_{\mathrm{d}}^{\mathrm{m}} \quad$ Frequency drop threshold for full support [Hz]

$G C_{c i} \quad$ Grid Code compliance index [-]

GP, NP Gross and Net payments [€]

$\mathrm{K}_{\mathrm{acc}}, \mathrm{K}_{\mathrm{ex}}$ Accelerative de-loading and $\mathrm{KE}$ extraction coeff.

KE Kinetic energy

MPT Maximum power tracking

$\mathrm{P}_{\mathrm{c}} \quad$ Installed generation capacity [MW]

$\mathrm{PN}_{\min } \quad$ Minimum applicable penalty [€]

PF Penalty factor [-]

$\mathrm{P}_{\mathrm{rr}} \quad$ Required reserve during time-window [MW]

$\mathrm{R} \quad$ Droop constant of synthetic response [-]

$\mathrm{R}_{\mathrm{f}} \quad$ Risk Factor [-]

RoCoF Rate of change of frequency [Hz/s]

A. B. Attya is with the Department of Engineering and Technology, University of Huddersfield, Huddersfield, UK (corresponding author, email: a.attya83@gmail.com)

J.L Dominguez-García is with the Electrical Engineering Department, Catalonia Institute for Energy Research, Barcelona, Spain.
SR Synthetic response

$\mathrm{T}_{\mathrm{f}} \quad$ Width of the evaluation time window [s]

$\mathrm{T}_{\mathrm{j}}$ and $\mathrm{T}_{\mathrm{c}}$ Time constants of SR originator [s]

WPP Wind power plant

$\mathrm{WPP}_{\mathrm{nc}} \quad \mathrm{WPP}$ nameplate power capacity [MW]

WS Wind speed $[\mathrm{m} / \mathrm{s}]$

WTG Wind turbine generator

$\delta_{\Delta P} \quad$ Power deviation factor [-]

$\delta_{G C} \quad$ Incurring grid code violation [-]

\section{INTRODUCTION}

$\mathrm{T}$ HE majority of countries worldwide has committed to fight against the climate change, and some plans and actions have been defined (e.g. COP21) [1]. This will lead to a large penetration of renewable energy into the generation mix, especially wind, which can change the power system behavior as well as the key players participating in system services for secure and stable operation (e.g. frequency support, power balancing, and oscillation damping) [2]. Currently, there are dedicated markets to provide such ancillary services, where generation units can participate and bid their anticipated contributions according to certain schemes [3]. The renewable energy units are not actively participating in these markets, since the dominating regulations are developed to match past status of power systems with large inertia and conventional generation. However, this needs to change, where several projects and research efforts are exploiting potential market modifications to enable the participation of renewable power plants, and acknowledge some responses and services that are mandated and seen 'natural' and possible based on typical responses of synchronous generation.

The provision of frequency support by wind energy is a key topic that has been investigated since a decade $[4,5]$. The literature proposes two main concepts, pitch deloading and kinetic energy (KE) extraction, to enable wind turbine generators (WTGs) to provide synthetic inertia and primary frequency response $[6,7]$. A third method has been exploited recently, which relies on accelerating the WTG rotor by a certain ratio to secure a reasonable power reserve to be utilized to provide frequency support $[8,9]$. The main objective of these concepts is to secure a certain predefined amount of active power surge, i.e. supportive steep increase in output power, to tackle frequency events and curtail power imbalance causing such drops. The widely studied concept, and adopted by some WTG manufacturers, is pitch deloading, where WTG output is deloaded by a certain margin below optimum generation, i.e. Max. Power Tracking (MPT) curve, through the integration of supplementary controls [10]. There are two types of deloading, Delta and Balanc: Delta method de-loads WTG output by a 
certain ratio of its MPT output, typically 10-15\%. Meanwhile, Balance deloading curtails the WTG output by an absolute value of power, that does not have a typical value, as it relies on WTG rating and required amount of support (e.g. it can be 0.25 MW for a 2 MW WTG) [11]. The KE extraction concept is more favorable to wind power plants (WPPs) operators, as it does not apply sustained deloading on WPPs output at normal operation, hence, the amounts of sold wind energy are not curtailed. However, it can be more threatening to power system stability, as there is no secured reserve. In addition, this concept implies a recovery period, where the extraction process stops at a certain threshold rotor speed, and the WTG output is kept below MPT temporarily to allow the WTG to accelerate to the nominal rotor speed. This recovery stage can drag the power system to a second frequency event [12]. There is always the challenge of providing sustainable support in spite of the variability of wind speed (WS) [13].

Typically, less focus is drawn on quantifying the impact of support methods on power systems [14], and their compliance with both the grid codes and system needs, and the corresponding compensations and penalties that should be paid/applied by the procurers of such services. Non-compliance with grid codes is treated in different ways worldwide, for example, in Australia, the Law enforces grid code, and noncompliance under certain conditions is considered as a civil offense [15]. In Germany, there is not unified grid code. However, the Law mandates that every system operator (SO) to announce transparently the requirements to connect a generation unit or a large load to its transmission network, and non-compliance is not penalized. WPPs are not mandated to provide frequency support, but they have to limit ramping up their output by a certain rate, and they must keep connected even if the frequency drops to $47.5 \mathrm{~Hz}$ [16]. Likewise, in Ireland, they do not enforce frequency support on WPPs. Even more, when SO raised a recommendation of relaxing trip limit of RoCoF relays from 0.5 to $1 \mathrm{~Hz} / \mathrm{s}$ to accommodate high penetration of wind power, it was rejected because many WTGs' relays rely on old technology, and their trip limit cannot be amended [17]. In Denmark, SO adopts a conservative approach, as it enforces Delta frequency support control. This means that every WPP with total output power of more than 25 MW at point of connection must keep its output below the available (de-loading) and provide controllable signals to $\mathrm{SO}$ that come effective within no longer than $2 \mathrm{~s}$ and complete its function within 10s from the initiation of frequency event [18].

There are other frequency-related services procured through markets (e.g. secondary and tertiary services, firm frequency response, and balancing), which in some countries are paid only by the actual amounts of support energy [19]. The penalties are applied only if generation is changing in a direction opposing grid requirements (e.g. if generation ramps down during frequency drop) regardless its amount. UK National grid obligates new generation units to do on-site tests to examine their behavior under special events described in the grid code, this allows generation units to receive a compliance certificate [20]. However, SO does not apply non-compliance penalty, but if non-compliance is observed to be sustainable, National grid asks the generation unit operators to provide a technical report explaining the causes of non-compliance and possible solutions to avoid it in the future. The report should be submitted within a duration of 56 days, and if non-compliance persists for a certain duration, the unit can be forced to disconnect. The National Grid also obligates units of intermittent input mechanical energy to maintain their output when frequency drops, such that drop in output is limited to $5 \%$ of power plant output when frequency drops to $47 \mathrm{~Hz}$. They also ask every offshore WPP that is connected via an HVDC connection, to record real time frequency data at the point of connection to the onshore grid. In summary, current practices do not apply dynamic verification and/or performance evaluation of WPPs as frequency support providers.

In line with the previous discussion, and foreseen changes in dynamic responses of power systems due to deep wind energy penetration and large synchronous generation shutdown, novel and stricter rules for ancillary services provision are essential to alleviate unexpected dynamics that can be critical. The need for verification methods of WPPs performance as ancillary services providers is strongly seen by different entities [21].

This paper proposes a novel method to quantify the performance of WPPs concerning frequency support from two aspects, its compliance with grid codes and divergence from bid amounts of active power support. The proposed method provides a practical procedure for future markets of frequency services under high penetration of wind energy from two aspects, new markets for inertia response, and a compensatory scheme for adequate responses if such service provision is mandatory. The quantitative method encompasses two main dynamic parameters that are evaluated during a certain predefined time window, where the actual performance is compared to the synthetic response generated by a certain generic control that is able to provide an ideal response from a grid code requirements perspective. The paper also provides an insightful and comprehensive study to reveal the impact of the key variables that influence the support methods integrated to WTGs. This study considers WS conditions, support concept, tuning of key control parameters, and the width of the time window to evaluate WTG performance during events.

\section{Methodology}

This paper aims to bridge the gap between grid code compliance and market compensations paid to WPPs, where a dynamic penalizing method is proposed, which acknowledges the bidding ahead of the WPP and the applied grid code through an aggregated approach such that the penalty is assessed within a certain time-window not on an event-by-event basis. In addition, the impact of key parameters of the applied support methods is exploited. The proposed penalty factor $(\mathrm{PF})$ reflects the integration of different conditions, including Grid Code compliance index $\left(G C_{c i}\right)$, the amount of the reserve bid at the head of time window (i.e. reserve power and support energy biddings), and width of evaluation time window $\left(\mathrm{T}_{\mathrm{f}}\right)$. The influence of $T_{f}$ is examined for different values and allocation approaches related to frequency dynamics as explained later. 
The bidding amounts of average power support within $5 \mathrm{~s}$ from event initiation $\left(\Delta \mathrm{P}_{5}\right)$ is converted to a per unit value in comparison to WPP capacity factor. For example, if the WPP nameplate capacity is $500 \mathrm{MW}$, and it has a capacity factor of $40 \%, \Delta \mathrm{P}_{5}$ of $20 \mathrm{MW}$ is converted to $0.1 \mathrm{pu}$ using (1),

$\Delta \mathrm{P}_{5 \mathrm{pu}}=\frac{\Delta \mathrm{P}_{5}}{\text { WPP nameplate capacity } * \mathrm{CF}}$

where CF and $\mathrm{WPP}_{\mathrm{nc}}$ are the annual capacity factor and nameplate capacity of the WPP respectively, and $\Delta \mathrm{P}_{5 \mathrm{pu}}$ is the per unit value of $\Delta \mathrm{P}_{5}$. This parameter is used to measure the actual power reserve at each time step, according to the prevailing WS conditions in relation to WPP compliance with the enforced grid code.

The PF represents a certain reduction percentage of the overall payment to the WPP according to its performance within the previous bidding time window. For example, if $\mathrm{PF}$ is $20 \%$, the WPP will receive $80 \%$ of the gross payment (GP). This could be seen as a fair trade to WPPs, because the penalty somehow relates to reserve prices during the given timewindow. However, to ensure power system stability, a minimum limit is applied to the penalty absolute value $\left(\mathrm{PN}_{\mathrm{min}}\right)$. $\mathrm{PN}_{\min }$ can be set as a dynamic or static value, in this paper, a compromise is proposed, as $\mathrm{PN}_{\min }$ is obtained using (2)

$\mathrm{PN}_{\text {min }}=\mathrm{P}_{\mathrm{rr}} \cdot\left(\frac{\mathrm{CF} \cdot \mathrm{WPP}_{\mathrm{nc}}}{\mathrm{P}_{\mathrm{c}}}\right) \cdot \mathrm{C}_{\mathrm{P}}$

where $\mathrm{P}_{\mathrm{rr}}$ and $\mathrm{C}_{\mathrm{P}}$ are the overall required reserve and the decided support power price within the given time-window respectively. $P_{c}$ is the installed generation capacity of the power system. The $G C_{c i}$ is cumulative within $\mathrm{T}_{\mathrm{f}}$, as explained in the next section, as its value is aggravated for the continuous and higher non-compliance leading to the multiplication of PF, which adds further security to power system stability. The PF can reach a negative payment that actually represents a deduction from the calculated net payment of the next timewindow as obtained using (3), (4) and (5)

$\mathrm{GP}_{i}=\Delta \mathrm{P}_{30} \cdot \mathrm{C}_{\mathrm{P}}+\Delta \mathrm{E}_{30} \cdot \mathrm{C}_{\mathrm{E}}$

Penalty $=\left\{\begin{array}{r}0, G C c i \approx 1 \\ \max \left(\mathrm{GP} \cdot \mathrm{PF}, P E N_{\text {min }}\right), G C c i<1\end{array}\right.$

$\mathrm{NP}_{i}=\mathrm{GP}-$ Penalty $+\min \left(0, \mathrm{NP}_{i-1}\right)$

where NP stands for net payments, and suffix $i$ refers to the index number of the time-window, i.e. $i-1$ indicates the previous evaluation window. $C_{E}$ and $C_{P}$ are the power and energy prices for frequency services. $\Delta \mathrm{P}_{30}$ and $\Delta \mathrm{E}_{30}$ are the average support power energy within 30 s starting from a given time point, during the event, decided by the SO. The $5 \mathrm{~s}$ and 30 s time intervals are selected, due to the common practice and recommendations of grid codes to regulate the provision of inertia response and primary reserve. The first $5 \mathrm{~s}$ of the event experiences the inertia response, either naturally, which is the case in synchronous generators, or synthetically for renewables and energy storage. The inertia should tackle and mitigate the incident frequency nadir caused by the power imbalance event, where the nadir commonly occurs between 5 and $15 \mathrm{~s}$ of the event [22]. The generation unit should provide the full available reserve within 10-30s of the event [23], and some codes expect that generation units can detect frequency drops and adjust output in 30s [24].

To this extent, the paper aims to assess NP for WTGs/WPPs according to their actual contributions to frequency support, submitted bids, and compliance with grid code. The PF is a part of this assessment because it deducts GP, i.e. maximize the incentive paid to WPP if it responds properly. It can be noticed that, GP calculation is straightforward and relies on the amounts of support energy and power that have been provided during frequency event(s). However, it is challenging to estimate the $\mathrm{NP}$, as it also relies on evaluating the performance of wind power assets during the provision of these amounts. This is because of the complexity of the problem, where the WTG/WPP has to comply with the grid code, fulfil the bids, and accommodate WS changes. The violation of either of these restrictions can threaten the dynamic stability of power system, mainly at high penetration of wind power in the generation mix. This method aims also to mitigate WPPs from trading irresponsibly on frequency services market, jeopardizing system dynamics and security, i.e. providing more support energy does not necessarily mean higher payments, but it solely relies on system requirements during each event.

\section{GRID CODE COMPLIANCE INDEX}

The proposed method applies the frequency test signal shown in Figure 1(a) to act as a reference case. The compliance of bidding amounts, submitted by the WPP, is judged against the active power response of the grid code shown in Figure 1(b). This paper applies real frequency data of the UK National Grid in 2016 with 1 reading/s [25], in order to test the proposed method under real conditions, including the highly dynamic frequency, diverse steepness and duration of the events, and unpredictable initiation points of events. For example, it is challenging to identify precisely the instant at which a given frequency event starts, as the frequency is oscillating at all times as shown in Figure 2. The system behavior is not only affected by the amount of support energy provided in total, but also the time pattern of providing it, hence it requires a more sophisticated method to evaluate WPPs performance. The proposed method splits the ideal active power response into four zones, and each zone has unique penalizing rules as illustrated in Table I. A Risk factor $\left(\mathrm{R}_{\mathrm{f}}\right)$ is given for each zone that acts as an indicator to the impact of non-compliance on system stability, hence $R_{f}$ decays as RoCoF moves to safer zones. To facilitate the assessment process, the four zones are identified based on the instantaneous RoCoF, for example, if the $\mathrm{RoCoF}$ is close to the tripping limits of RoCoF relays (i.e. $\pm 0.5 \mathrm{~Hz} / \mathrm{s}$ according to some grid codes [26]), this indicates an early stage of a frequency event; Zone 1. In this zone, it is favorable for power system stability to have very responsive generation units with high step change in active power, which is achievable by WPPs given suitable WS conditions. Thus, deviations above synthetic response (SR) are not penalized if they exceed the Upper limit. This changes in Zone 2, as it is required to regulate the power support to avoid frequency overshoots straight after the frequency dip. 
The deviations above SR are penalized, but with more generous margin compared to deviations below SR, as it can curtail/delay the power system's ability to maintain an acceptable frequency, i.e. avoid load-shedding protocols. In Zone 3, the same applies, but with equal margins above and below SR, as it is expected that the provided support can be less due to nature of applied support method and/or WS conditions. The deviations are always weighted against instantaneous SR that can be obtained using a simple controller shown in Figure 3. This controller acts as a generic response originator, and a datum to compare with WTG/WPP actual response on per unit basis [27], where actual chronological data of frequency are processed through SR originator. The controller parameters are maximum and minimum limits of power support proportional components; $\Delta \mathrm{P}^{\mathrm{p}}{ }_{\text {min }}$ and $\Delta \mathrm{P}^{\mathrm{p}}{ }_{\text {min }}$ respectively, $\Delta \mathrm{P}_{\text {min }}^{\mathrm{d}}$ and $\Delta \mathrm{P}_{\text {min }}^{\mathrm{d}}$ are the limits of the derivative component. $R, T_{j}$ and $T_{c}$ are the droop constant, time constant to obtain RoCoF, and time constant of the low-pass filter respectively (numerical values are in Table II). The implemented grid code, on which SR parameters are decided, is generic and complies with the common requirements related to frequency stability, addressed by the European transmission systems operators [27]. Finally, in Zone 4, frequency should have stabilized at a new steady state, hence allowed deviations are wider, but still within upper and lower limits of the grid code. The allowance below SR is less than above to mitigate the possibility of successive drops.

The $G C_{c i}$ is obtained using (6) and (7), which considers the risk caused by noncompliance reflected by the value of $R_{f}$, and the incurring deviation,

$G C_{c i}=1-R_{f} \cdot\left(1-e^{-x \cdot\left|\delta_{G C}(t)\right|}\right)$, where $0 \leq G C_{c i} \leq 1$

$\delta_{G C}(t)=\left\{\begin{array}{c}0 \text { Actual deviation } \leq \text { Allowed deviation } \\ \text { Actual deviation } \%-\text { Allowed deviation } \% \text { else }\end{array}\right.$

where $\delta_{G C}(\mathrm{t})$ is the incurring violation within time while the Actual and Allowed deviations are ratios of SR. The factor $x$ is a fine tuner that can be set to a constant or dynamic value to alter (widen or tighten) the rate of exponential decay, incurring due to noncompliance with the grid code applied. This is subject to the decision of SOs and design of frequency support market, in this paper, $\mathrm{x}$ is set to one as a default value.

\section{A. Overall penalty factor evaluation}

This factor is a conclusive index for the performance of WTG/WPP during severe events, and it can be applied to the entire frequency oscillations. The PF combines the financial penalties arising from noncompliance with the grid code, in addition to the mismatch between bid amounts of frequency support and the actual provided amounts during the event within the considered time interval. The work in [28] defined two indices to represent average power support within $5 \mathrm{~s}$ and 30 s from event initiation, $\Delta \mathrm{P}_{5 \mathrm{~s}}$ and $\Delta \mathrm{P}_{30 \mathrm{~s}}$ respectively. A bidmatch parameter is based on $\Delta \mathrm{P}_{5 \mathrm{~s}}$ and $\Delta \mathrm{P}_{30 \mathrm{~s}}$ using (8),

$\delta_{\Delta P}(t)=1-\frac{\Delta P_{a}}{0.5 *\left(\Delta P_{5 S}+\Delta P_{30 S}\right)}, \delta_{\Delta P} \geq 0$

where $\Delta \mathrm{P}_{\mathrm{a}}$ is the actual average support during the event in comparison with the WTG/WPP output just before the event, and $\delta_{\Delta P}$ is the power deviation factor, where zero is the best value indicating full matching with bid amount, while one is the worst. It can be noticed that the given formula assumes that $\Delta \mathrm{P}_{\mathrm{a}}$ is always less than bid amount, however, if this is not the case, $\delta_{\Delta P}$ is set to zero. The values of $\Delta \mathrm{P}_{5 \mathrm{~s}}$ and $\Delta \mathrm{P}_{30 \mathrm{~s}}$, for the examined methods explained in the next subsection are found in Table III. The authors have applied Monte Carlo Simulations to obtain these bids [28], where a probabilistic method was proposed to estimate the support energy and power bids of WTG under the same support methods applied in this paper. The work presented in this paper is a development of the full picture of incentivizing and penalizing WPPs as provider of frequency support, where the proposed method estimates NP based on grid code compliance and fulfilling submitted bids. The proposed method is targeting moderate and deep frequency drops, not minor deviations that occur during normal operation.

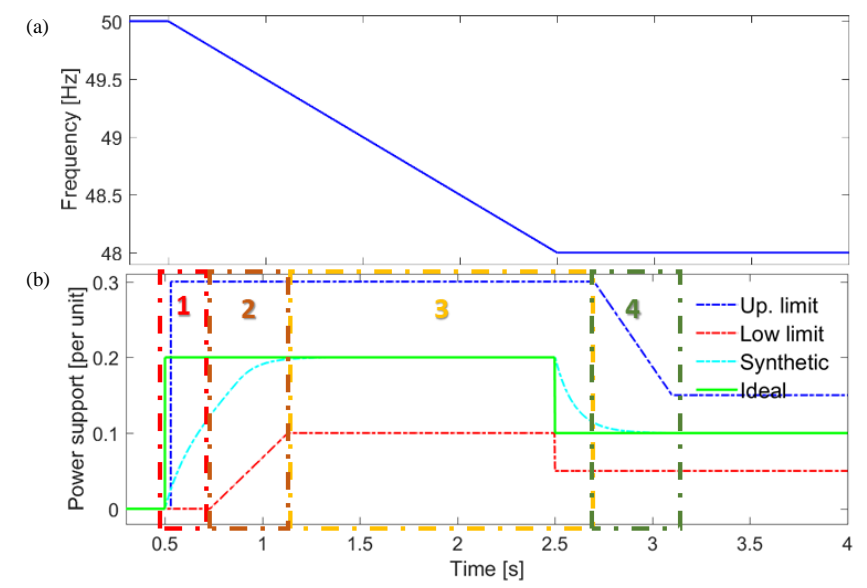

Figure 1. Frequency a) test frequency event, b) required active power support.

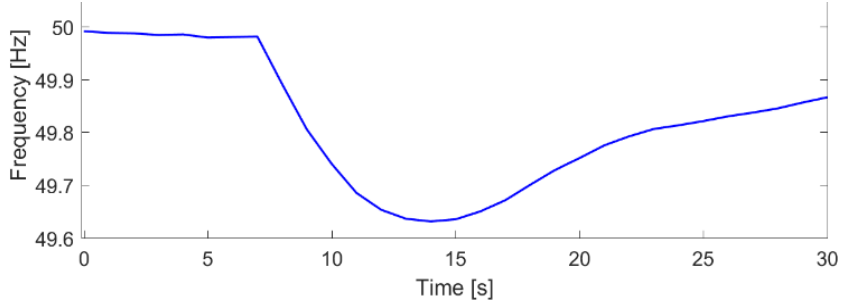

Figure 2. Actual frequency in UK grid (worst event in January 2016).

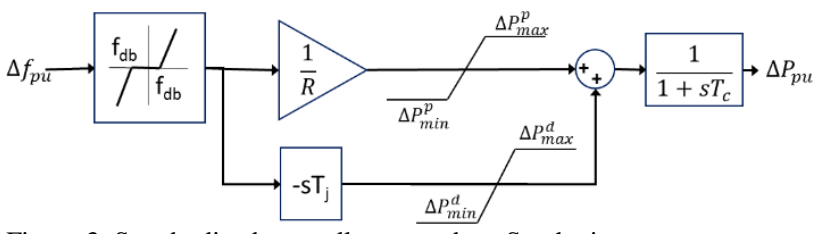

Figure 3. Standardized controller to produce Synthetic response.

TABLE I. FOUR ZONES OF COMPLIANCE AND FREQUENCY SUPPORT ASSESSMENT (\% of SR, and RoCoF is in $\mathrm{Hz} / \mathrm{s}$ )

\begin{tabular}{|c|c|c|c|c|c|c|}
\hline \multirow{2}{*}{$\begin{array}{l}\text { Zone } \\
\text { Penalized }\end{array}$} & & early iner & & 2: late inertia & 3: primary & 4: retreating \\
\hline & \multicolumn{3}{|c|}{$>50 \%$ below } & $\begin{array}{l}>50 \% \text { above } \\
>25 \% \text { below }\end{array}$ & $\begin{array}{l}>50 \% \text { above } \\
>50 \% \text { below }\end{array}$ & $\begin{array}{l}>75 \% \text { above } \\
>50 \% \text { below }\end{array}$ \\
\hline $\mathrm{R}_{\mathrm{f}}$ & 1.4 & & & 1.3 & 1.15 & 1 \\
\hline \multirow[t]{2}{*}{ Condition } & \multicolumn{3}{|c|}{ RoCoF $<-0.3$} & $\begin{array}{l}-0.3 \leq \mathrm{RoCoF} \leq- \\
0.1\end{array}$ & $\begin{array}{l}-0.1<\mathrm{RoCoF} \\
\leq 0.1\end{array}$ & $\begin{array}{l}-0.05<\mathrm{RoCoF} \\
\leq 0.05\end{array}$ \\
\hline & \multicolumn{6}{|c|}{ Frequency is outside the applied deadband $(30 \mathrm{mHz})$} \\
\hline \multicolumn{7}{|c|}{ TABLE II. SYNTHETIC RESPONSE PARAMETERS } \\
\hline $\mathrm{R}$ & $T_{j}$ & $\mathrm{~T}_{\mathrm{c}}$ & $\Delta \mathrm{P}^{\mathrm{c}}$ & ${ }_{x} \& \Delta \mathrm{P}_{\text {min }}^{\mathrm{d}}$ & $\Delta \mathrm{P}_{\max }^{\mathrm{p}} \& \Delta \mathrm{P}_{\mathrm{r}}^{\mathrm{p}}$ & \\
\hline 0.07 & $10 \mathrm{~s}$ & $0.1 \mathrm{~s}$ & \pm 0 . & ger unit & 0.1 and $-0.9 \mathrm{p}$ & er unit \\
\hline
\end{tabular}




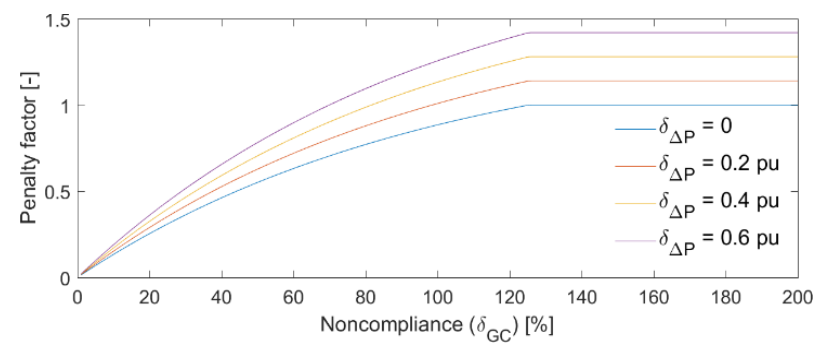

Figure 4. Variation of penalty factor against non-commitment indices (Zone 1).

SOs can apply this method to assess the contributions of involved WTGs/WPPs according to their biddings at the end of submission time window, when these biddings should be actually applied if system suffers frequency event(s) during the considered interval. The PF within $\mathrm{T}_{\mathrm{f}}$ is obtained using (9) relying on the two proposed parameters; $\delta_{\Delta P}$ and $G C_{c i}$,

$\mathrm{PF}=\frac{1}{\left(T_{f}\right)^{2}} \cdot \int_{t_{o}}^{t_{o}+T_{f}}\left(1-G C_{c i}(t)\right) \cdot \int_{t_{o}}^{t_{o}+T_{f}}\left(1+A_{\delta} \cdot \delta_{\Delta P}(t)\right)$

where $\mathrm{A}_{\delta}$ is a tolerance factor, $\mathrm{t}_{\mathrm{o}}$ is the initial time point of the event (i.e. when it violates frequency deadband). It is of note that, PF reflects the cumulative result of non-compliance and poor bidding. However, non-compliance has higher impact. This is a fair evaluation method, as it splits between the two components as illustrated in Figure 4. The PF is aggravated as $\delta_{\triangle P}$ grows, but a tolerance is granted to WPPs to deviate from bid amount, which is represented by $\mathrm{A}_{\delta}$. In this paper, the allowed margin is $30 \%$, i.e. $A_{\delta}=1-0.3=0.7$. The processes of applying this method in the real world and the corresponding emulation, used in this paper, are illustrated in Figure 5, while the timeline of the real process is described in Figure 6. It is of note that, earlier disclosure of evaluation report by SO is preferable, as it provides a sort of 'feedback' on WPPs performance (e.g. daily or weekly report) so that WPPs re-tune their controls if necessary, hence, their response becomes more beneficial to system stability, and avoids unnecessary penalties.

\section{EXAMINED SUPPORT METHODS}

The cornerstone of frequency support methods is to secure a sustainable and adequate support that changes according to frequency dynamics regardless the pertaining WS conditions. The NREL 5MW detailed Simulink model [29] is developed to integrate three supplementary controllers separately as depicted in Figure 7 to enable the WTG to provide frequency support. The term available refers to WTG output when it applies the conventional MPT. When the frequency violates the applied safe margin $\left(f_{\text {low }}\right)$, support power increases gradually using a droop gain until frequency drop reaches a predefined threshold $\left(\mathrm{f}_{\mathrm{m}}{ }_{\mathrm{d}}\right)$, where WTG provides the full available support.

\section{A. Pitch deloading}

This method deloads the WTG output continuously by a constant ratio $\left(\mathrm{D}_{\mathrm{F}}\right)$ from the available output, where the reference pitch angle and power signals are updated continuously to maintain a predefined $\mathrm{D}_{\mathrm{F}}[11]$.

\section{B. Kinetic energy extraction}

This method is based on increasing reference torque above the available input torque during frequency event, making the

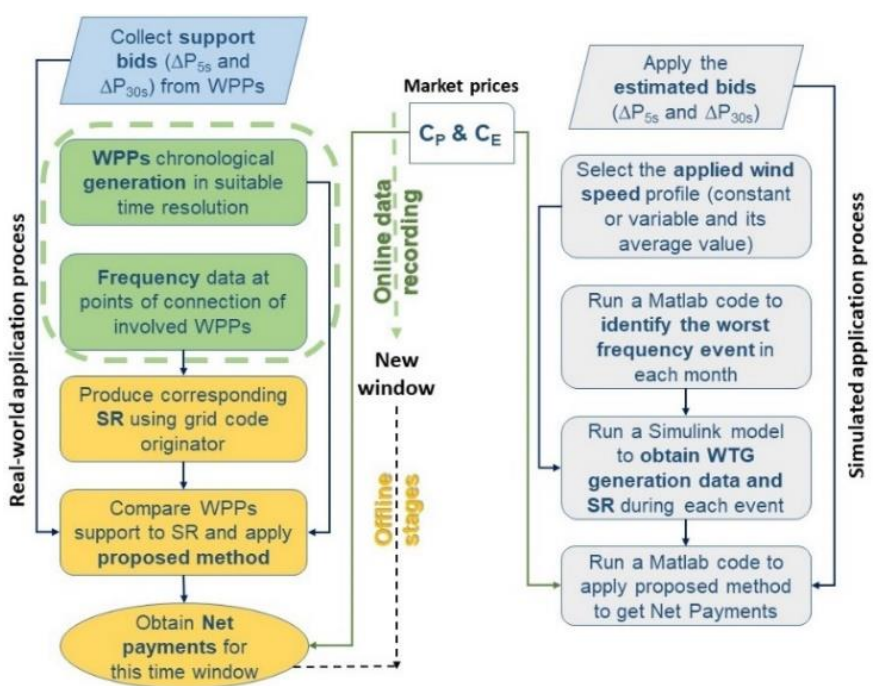

Figure 5. Flowcharts of actual application and hypothetical validation of the proposed valorization method.

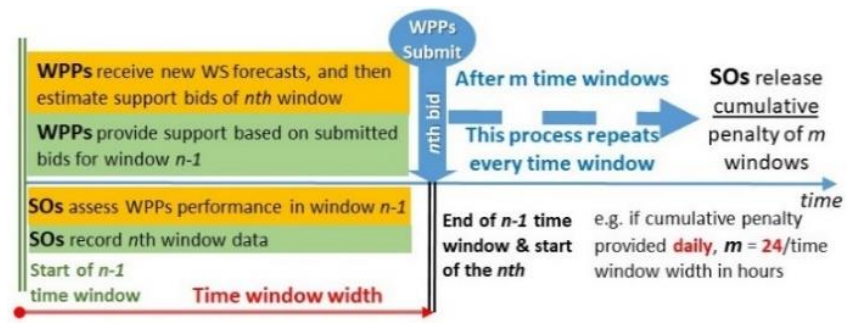

Figure 6. Timeline of the whole process (bidding, provision and evaluation).

WTG extracts some of the KE stored in rotating parts to provide support power. This method does not cause major energy losses during normal operation, i.e. no deloading is applied, where the WTG is following MPT when there is no frequency event. However, it provides support for a short time, and is highly vulnerable to WS conditions, during and after the event. The extraction factor $\left(\mathrm{K}_{\mathrm{ex}}\right)$ is regulated by frequency drop severity through similar linear droop applied in the other methods $(1 \leq$ $\left.\mathrm{K}_{\mathrm{ex}} \leq 1.15\right)$. The extraction process stops when rotor speed reaches the low threshold. The recovery to normal speed starts when frequency stabilizes within the safe margin, where the torque is kept below the available input to accelerate the rotor.

\section{Accelerative deloading}

This method has the privilege of being applied to all variable speed WTGs, mainly when it is not desirable to apply special pitch control methods, or the WTG is not equipped with a pitching system. Nevertheless, it depends on the margin of rotor speed variation, according to the rating of the integrated power electronics interface. This method aims to reduce reference torque by a certain ratio $\left(\mathrm{K}_{\mathrm{Acc}}\right)$ below the normal reference value, hence the WTG accelerates, as the demand is slightly less than the available mechanical torque and the electrical output is deloaded during normal frequency conditions. This reduction factor has an upper limit to ensure that the maximum allowed rotor speed limit is not violated $\left(0.85 \leq \mathrm{K}_{\mathrm{Acc}} \leq 1\right.$, at $\mathrm{K}_{\mathrm{Acc}}=0.85$ full deloading is applied). $K_{\text {Acc }}$ is reduced gradually, when $f_{\text {low }}$ is violated, through a droop gain similar to that used in Pitch deloading. Therefore, the support is provided the extracted KE during deceleration, and approaching the optimum operation 
point when the torque reaches its non-deloaded value. Post event, the recovery to accelerated speed initiates within a predefined duration (30s in this paper).

The same ratio of $0.15 \mathrm{pu}$ is applied to the three support methods to achieve a consistent comparison. The responses of the test WTG to a moderate frequency events are displayed in Figure 8 to demonstrate the operation of the three methods, where MPT refers to conventional operation. It can be noticed that the initial operation point of WTG for each support method is different according to the method applied. For example, Pitch de-loading applies a sustained de-loading on the output during normal operation, and hence WTG output is below MPT before the event. Meanwhile, KE extraction applies MPT during normal operation, therefore WTG output is closer to MPT. The implemented support controllers' parameters are in Table IV.

\section{RESULTS AND DISCUSSION}

This section provides an extensive sensitivity study to exploit the impact of key factors that can influence PF evaluated by (9) including $\mathrm{f}_{\mathrm{d}}^{\mathrm{m}}, \mathrm{T}_{\mathrm{f}}$, and the implemented WS magnitude and profile where both constant and variable WSs are considered. Each factor represents a certain challenge facing the provision of frequency support by wind power, as $f_{m d}$ reflects the impact of controllers tuning, $T_{\mathrm{f}}$ indicates the influence of the applied evaluation scheme, and WS is the main uncertainty. A base case is defined where $\mathrm{f}_{\mathrm{md}}=49.8 \mathrm{~Hz}$ and WS is constant at $9 \mathrm{~m} / \mathrm{s}$. The event duration is the time between the instant at which frequency violates the safe deadband until it recovers to safety, hence each event has a different duration. Base case applies a constant $T_{f}$ of $30 \mathrm{~s}$, regardless the event duration. This can be reasonable for WPPs, as it is challenging to keep tracking the grid code requirements, and sustain the bid amount of frequency support for a longer duration. The other cases exploited are illustrated in Table V. In all cases, the actual amount of power support, i.e. $\Delta \mathrm{P}_{\mathrm{a}}$, is evaluated in comparison to the average value of actual WTG output within $5 \mathrm{~s}$ before frequency event initiates. PF is calculated for the worst event in each month from the real published frequency data of UK National Grid in 2016. In addition, the PF is evaluated for the test event shown in Figure 1 (b) and noted as 'Test' in Figure 9, the PF scored a wide range of values according to the nature of the event. Accelerative deloading is always higher than the other two methods. This returns to the adopted control where a big portion of the available reserve is released without strong dependency on the severity of frequency event, which causes considerable deviations from SR. The provided support has two components, reduced deloading margin and the extracted KE, which provides higher support at an early stage of the event before it starts to decay, as the WTG settles at a new slower rotor speed. KE extraction is more vulnerable to WS conditions, as the sustainability of support relies on the initial rotor speed, and it scores critical PFs compared to Accelerative deloading.

TABLE III. SUBMITTED BIDS OF POWER RESERVE FOR THE THREE METHODS

\begin{tabular}{l|l|l}
\hline Method/parameter & $\Delta \mathrm{P}_{5 \mathrm{~s}}$ & $\Delta \mathrm{P}_{30 \mathrm{~s}}$ \\
\hline Accelerative deloading & $0.14 \mathrm{pu}$ & $0.15 \mathrm{pu}$ \\
\hline Pitch deloading & $0.14 \mathrm{pu}$ & $0.145 \mathrm{pu}$ \\
\hline KE extraction & $0.135 \mathrm{pu}$ & $0.115 \mathrm{pu}$ \\
\hline
\end{tabular}

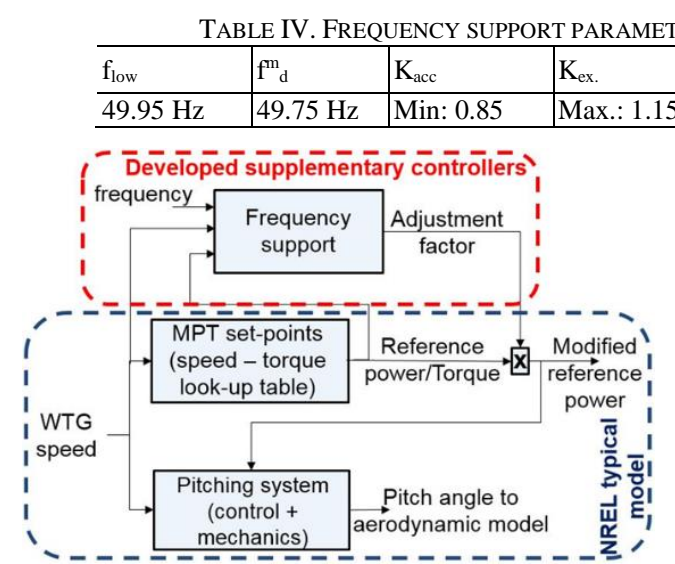

Figure 7 . Integration of controllers into NREL model.

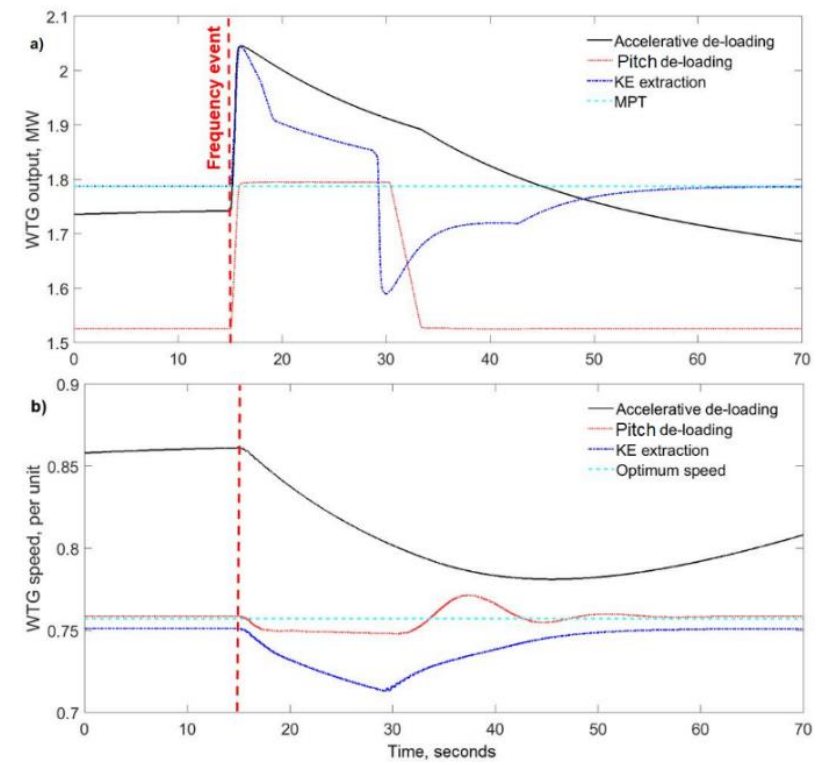

Figure 8 . WTG 5MW-rated, wind speed $=8 \mathrm{~m} / \mathrm{s}$ response to a frequency event under the three support methods: a) Output power; b) Rotor speed.

However, KE extraction has a merit over the other methods, as it maintains the provided support almost constant until the rotor speed reaches its lower limit. In addition, the amount of provided support is better regulated with respect to the incident frequency drop, which achieves higher compliance with the SR.

The frequency events that caused the worst PFs in April and May, and one of the lowest in September are displayed in Figure 10. It can be noticed that each event has a different time duration, and $\mathrm{T}_{\mathrm{f}}$ starts at the instant of frequency violation to the safe deadband. This means that the time interval embracing the frequency nadir in each of the three events is not considered in the estimation of PF, as it occurs outside $\mathrm{T}_{\mathrm{f}}$. The September event achieves a low PF also due to the similarity of the frequency event with the applied test frequency signal, which helps the WTG to respond in a more compliant way, as its controls are tuned mainly to comply with the required power response during this test event. Another factor is the frequency condition just before the nadir, where the deviation is relaxed in September compared to April and May, and frequency recovers faster to its nominal value. Limited frequency deviation just before the nadir improves and emphasizes the contributions of WTG in frequency support. 


\section{A. Impact of frequency threshold to release the full reserve}

The $\mathrm{f}_{\mathrm{d}}^{\mathrm{m}}$ is set to a tighter margin of $49.90 \mathrm{~Hz}$ to release the full available support under slighter frequency drops. This curtails the impact of droop regulation, and provides useful insights on the impact of very responsive support by the WTG. The other parameters are preserved from Base case, i.e. WS is constant at $9 \mathrm{~m} / \mathrm{s}$ and $T_{\mathrm{f}}=30 \mathrm{~s}$. Actually, the value of $\mathrm{f}_{\mathrm{d}}^{\mathrm{m}}$ is a key driver in the process of power support regulation during frequency events such that a higher value of $\mathrm{f}_{\mathrm{d}}^{\mathrm{m}}$, i.e. closer to safe deadband, provides higher $\Delta \mathrm{P}_{\mathrm{a}}$ for lighter deviations. However, the influence of $\mathrm{f}_{\mathrm{d}}^{\mathrm{m}}$ also relies on the adopted support method, which is reflected by the results shown in Figure 11. Comparing Base case of $\mathrm{f}_{\mathrm{d}}^{\mathrm{m}}=49.75 \mathrm{~Hz}$ and this case of tighter value at $49.90 \mathrm{~Hz}$, the parameter $\mathrm{f}_{\mathrm{d}}^{\mathrm{m}}$ increased the $\mathrm{PF}$ at the events that do not experience very deep frequency excursions (e.g. April and May) in cases of Pitch deloading and KE extraction methods.

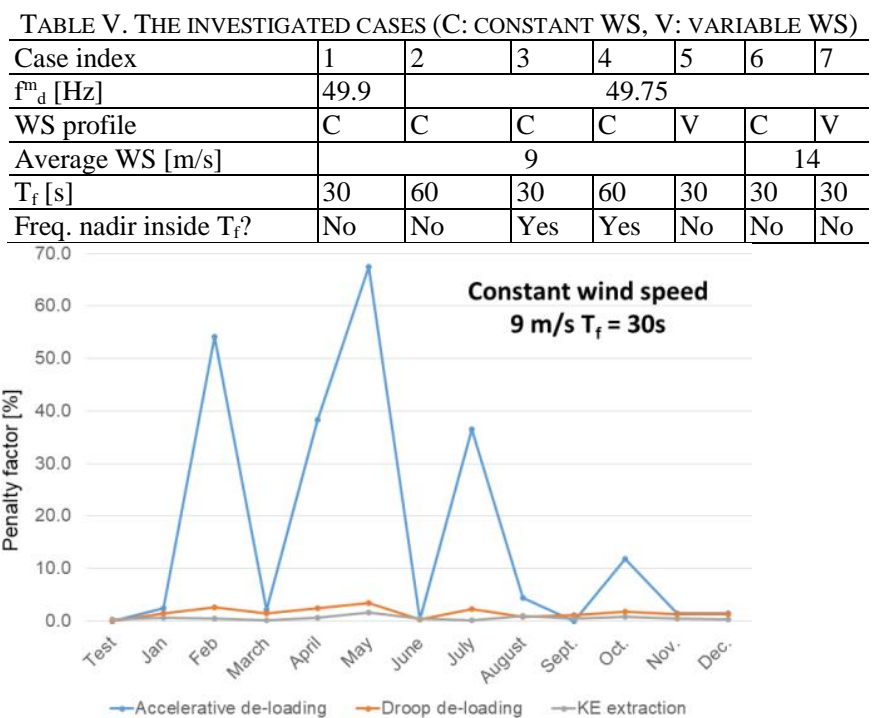

Figure 9. Base case results of PF.

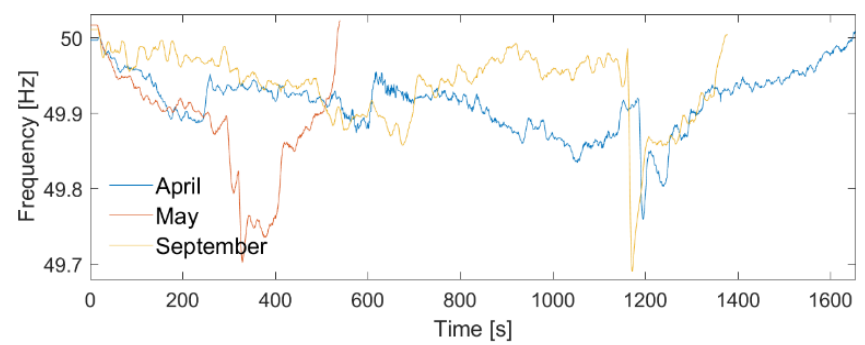

Figure 10. Frequency events of good (Sept.) and worst (April and May) PFs.

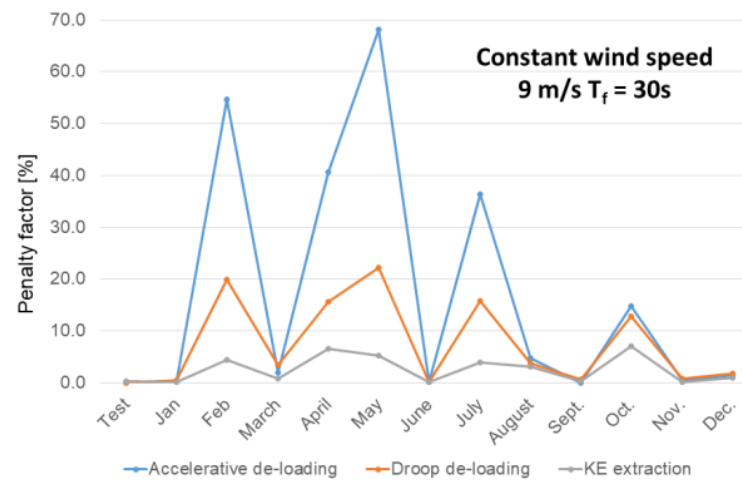

Figure 11. PF at a tight $\mathrm{f}_{\mathrm{d}}^{\mathrm{m}}$ of $49.90 \mathrm{~Hz}$.
The impact of $\mathrm{f}_{\mathrm{d}}$ is clearer when frequency deviation is better than $\mathrm{f}_{\mathrm{d}}^{\mathrm{m}}$, because there is a room for regulating the provided power support, which does not actually happen due to the tight $\mathrm{f}_{\mathrm{d}}$, and hence the amount of support is higher than required. On the contrary, when the frequency event is severe, the value of $\mathrm{f}_{\mathrm{d}}^{\mathrm{m}}$ does not manipulate the provided support, as the WTG is required to provide all the available support to tackle such deep excursions. The minor impact of $\mathrm{f}^{\mathrm{m}}{ }_{\mathrm{d}}$ on Accelerative deloading method is noticeable, since this method is rotor speed driven, where a slight change in reference speed leads to almost the same responsive power support, therefore the PF is not affected by changing $\mathrm{f}_{\mathrm{d}}^{\mathrm{m}}$. This also returns to the tight control region of $\mathrm{K}_{\mathrm{Acc}}$ within $15 \%$ of the WTG rotor speed to mitigate potential negative effects on the WTG mechanical components and structure as discussed in [30]. Comparing Figure 9 and Figure 11, there is a clear deterioration in PF; this can be because the system needs support for longer intervals, exhausting the WTG power reserve which mitigates the support capacity.

\section{B. Impact of PF evaluation time-window}

Two different approaches to set $T_{f}$ are tested: a constant value of $60 \mathrm{~s}$ that starts from the instant at which the frequency drops below the safe deadband. The second approach counts the same $T_{f}$ width, but starting from 10s before the occurrence of frequency nadir as illustrated in Figure 12. Moving $T_{\mathrm{f}}$ to include frequency nadir improves $\mathrm{PF}$, even if $\mathrm{T}_{\mathrm{f}}$ is extended to $60 \mathrm{~s}$. Applying the evaluation at frequency nadir can be favorable for WTG if WS conditions are reasonable, as the WTG has to provide all the available support. Hence, the deviations from SR are always within the allowed limits, which mitigates PF, and increases power and energy payments. This positive impact is clearer on Accelerative deloading because the provision of available support very rapidly is needed by the system and within the compliance margins.

\section{Impact of incident wind speed}

The WS applied data are real measurements of 1 reading/s, where the same array of WS is used for all cases with variable WS to provide a common ground for a fair and comprehensive comparison. The WS array is scaled up or down to achieve the average WS indicated in each case study, hence the applied WS profile is the same for all case studies that apply variable WS. This is to focus on examining the impact of the applied support method and the average WS magnitude at the WTG site, because if the WS profile is different in each case study, this could hide/screen the influence of the applied support method. The application of constant WS is widely accepted by the researchers on this topic, because the instantaneous minor variations in WS are almost filtered by the mechanical parts of the WTG (i.e., the gearbox, blades, pitching system, and inertia of rotating parts). Hence, this analysis includes some case studies with constant WS, to emphasis the impact of variable WS, and to be aligned with this research line of assuming the WS to be almost constant during frequency events [5]. The applied average WSs of 9 and $14 \mathrm{~m} / \mathrm{s}$ are common classes of moderate and high WS that can be found in WPPs sites. The same WS profiles used in [28] are applied, which represents 
what occurs in the real world when WPPs use the available WS forecasts to predict support bids using probabilistic analysis. The WPPs aim to fulfil these bids, subject to actual WS conditions that normally do not largely deviate from forecasted data [31]. It is of note that, applying randomly changing WS profile in a certain number of experiments until the error in PF stabilizes at an acceptable margin, i.e. Monte Carlo Simulation, would not affect the validity of the method proposed, but it could improve the accuracy of results obtained.

Three WS profiles are examined: constant WS of $14 \mathrm{~m} / \mathrm{s}$, variable WS of average $14 \mathrm{~m} / \mathrm{s}$ or $9 \mathrm{~m} / \mathrm{s}$. The values of $T_{f}$ and $\mathrm{f}^{\mathrm{m}_{\mathrm{d}}}$ are constant for the three investigated cases at 30s and 49.8 $\mathrm{Hz}$ respectively. The variable WS reduces the PF only when Accelerative deloading is applied as shown in Figure 13(a) in comparison to Figure 9. This returns to the adopted concept in this method where WS variation can improve the amounts of provided power support. Meanwhile, at constant WS, provided support is depleted at an early stage of the frequency event. This aligns with the observations on the marginal impact of $\mathrm{f}_{\mathrm{d}}$ in case of Accelerative deloading. Increasing WS to $14 \mathrm{~m} / \mathrm{s}$ does not prove to be clearly beneficial for all methods. However, it mitigates the differences between the methods at each event as shown in Figure 13(b) and (c). This is observed for both constant and variable WS profiles. The variable WS profile worsens the PF of Pitch deloading and $\mathrm{KE}$ extraction with slightly clearer impact on the latter. The variability of WS also shortens the extraction duration if the WS drops compared to WS value just before the frequency event initiates, mitigating the amount of extractable KE. The severity of the event triggers much worse impact for WS mainly under a variable profile. Although the WS in Case 7 is improved with respect to Base case, but the PF in February event is worsened. This can be justified by the fact that the PF reflects the non-compliance either with less or more support, so such higher WS leads to higher undesirable support, and this turns to be clearer under mild events. The PF of Accelerative deloading improves at constant and higher WS as shown in Figure 13 (b). This returns to the nature of this method where the available support relies on the accelerated rotor speed, and since rotor speed could not exceed its rated value, the provided support does not suddenly spike to a high value, as the margin between the accelerated speed and the maximum allowed speed is tighter. Therefore, it is recommended to shorten the closing-gate times for frequency markets, to help the WPPs to provide accurate bids, which reduces potential penalties evolving due to WS uncertainties.

\section{Examples of calculated net payment}

The cumulative payments are calculated for the 12 events are obtained using (5), for each support method in each case. The word cumulative refers to the implementation of the term ' $\mathrm{NP}_{i-1}$ ' which is the incurring payment (or penalty if it is negative) of the event in the month before. This paper considers the worst-case scenario where the WTG support performance is compensated at the 12 worst events of the year. To find $\mathrm{PN}_{\min }$ using (2), the average wind power penetration is assumed to be $20 \%$ of $\mathrm{P}_{\mathrm{c}}=120 \mathrm{GW}$, and with $\mathrm{CF}=40 \%, \mathrm{WPP}_{\mathrm{nc}}=50 \mathrm{GW}$.

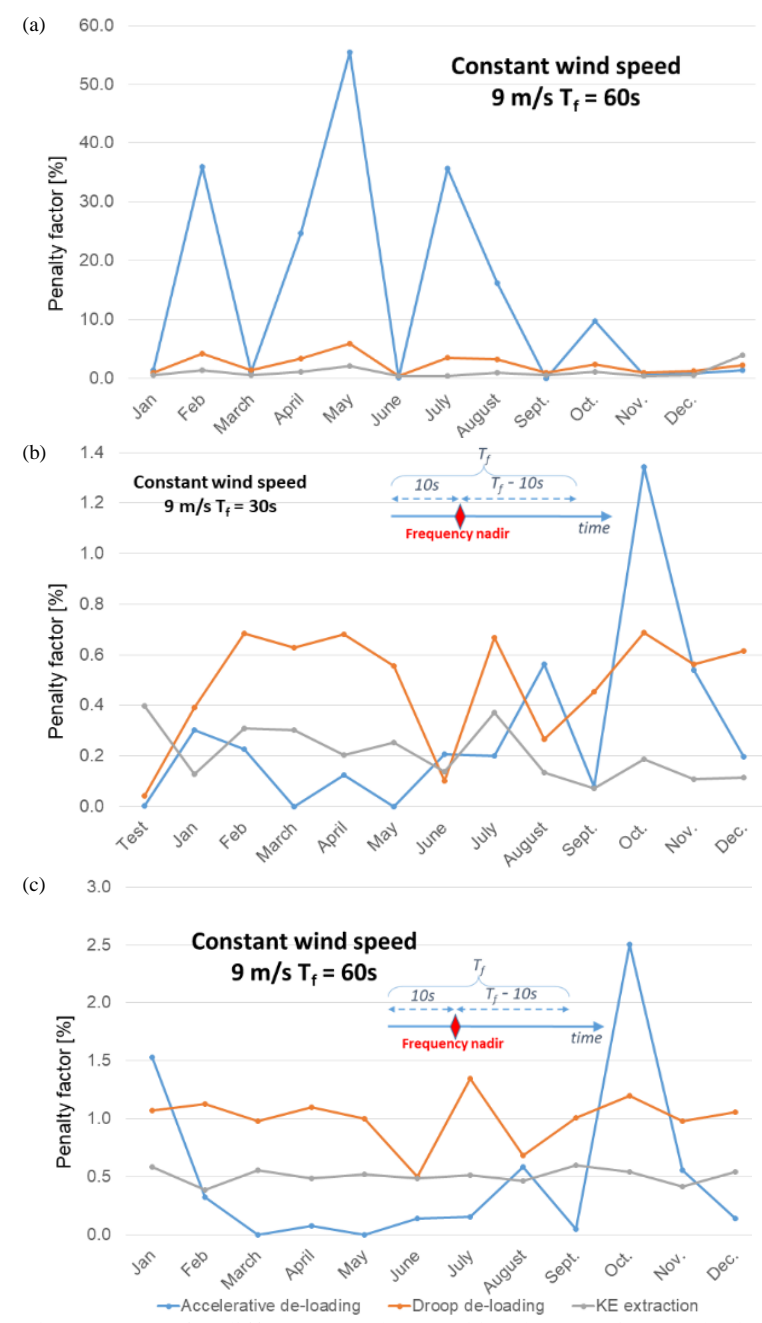

Figure 12. PF for different $\mathrm{T}_{\mathrm{f}}$ values and implementation methods.

The share of a $5 \mathrm{MW}$ WTG of $\mathrm{P}_{\mathrm{rr}}$ is obtained by equally distributing the given monthly average $\mathrm{P}_{\mathrm{rr}}$ by $\mathrm{WPP}_{\mathrm{nc}}$. $\mathrm{P}_{\mathrm{rr}}$ values of year 2016 in Table VI, are obtained from the data published by National Grid. $C_{P}$ and $C_{E}$ are assumed to be $25 € / M W$ and $1000 € / \mathrm{MWh}$ respectively.

The accurate values of $\Delta \mathrm{P}_{5}$ and $\Delta \mathrm{P}_{30}$ are obtained from the dynamic response of WTG to the event in each month under the examined scenario as explained in Figure 5. The 30s time span of $\Delta \mathrm{P}_{30}$ counts from the same start point of $\mathrm{T}_{\mathrm{f}}$, such that $\mathrm{PF}$ evaluation is consistent with subsidy calculation. $\Delta \mathrm{P}_{5}$ and $\Delta \mathrm{P}_{30}$ values are substituted in (4) and (5) to find NP. The cumulative payments of the three methods are shown in Figure 14. All the cases achieved positive incomes, except in Case 6 with a very slight cumulative penalty for the 12 events using Accelerative deloading. This can be justified by the high WS, which mitigates the WTG ability to accelerate to maintain the required deloading ratio without violating the limit of WTG rotor speed. Thus, the amount of provided support is limited, which increases the non-compliance and divergence form bid amount, leading to a higher PF. Conversely, Accelerative deloading shows some merit except in Case 7 that also applies variable high WS, worsening the performance of Accelerative deloading as previously explained. KE extraction has a clear privilege on Pitch deloading when WS is higher, but it has limited incomes 


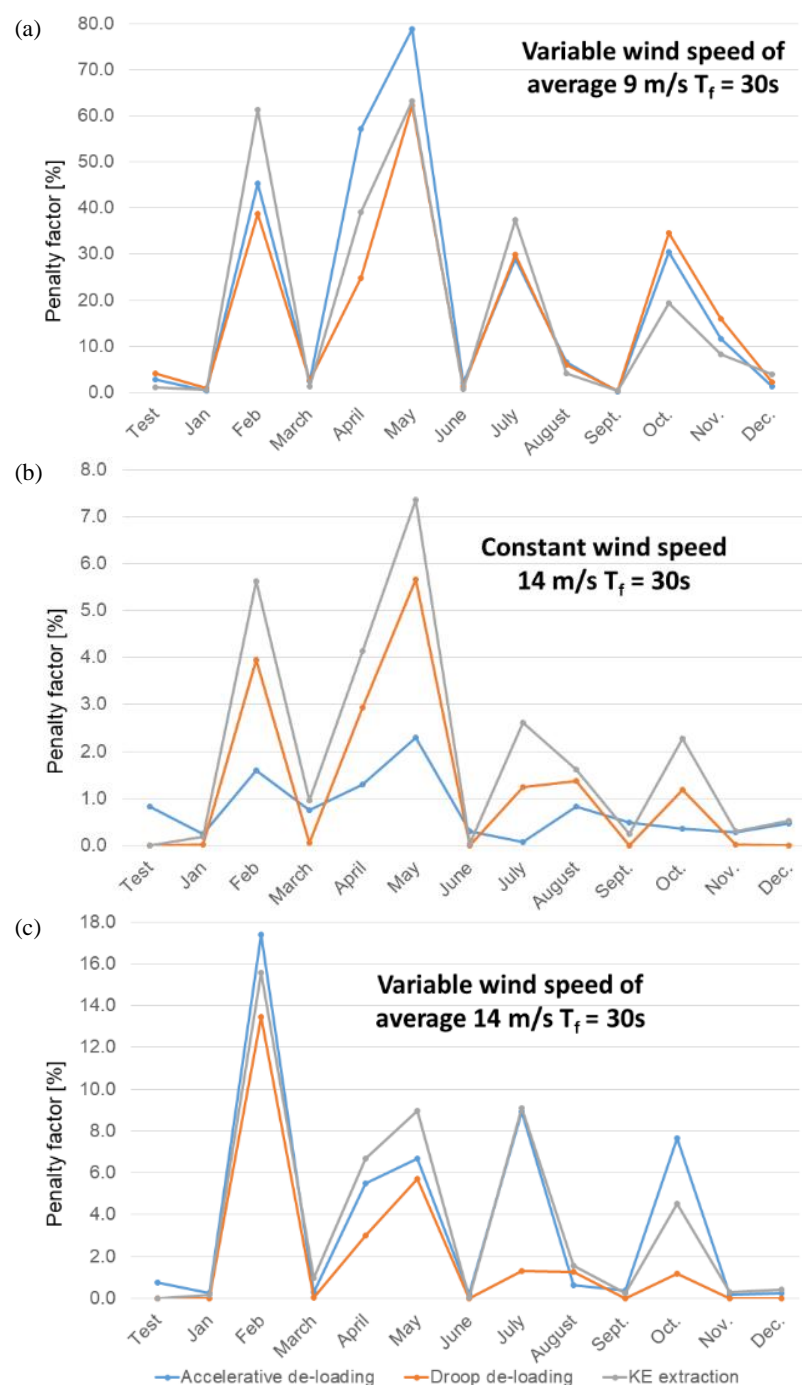

Figure 13. PF for different wind speed values and profiles.

TABLE VI. REQUIRED PRIMARY RESERVE (PRR) MONTHLY IN GW (2016). \begin{tabular}{l|l|l|l|l|l|l|l|l|l|l|l|l|l|l|l|l|}
\hline Jan & Feb & Mar & Apr & May & June & Jul & Aug & Sept & Oct & Nov & Dec \\
\hline
\end{tabular} \begin{tabular}{l|l|l|l|l|l|l|l|l|l|l|l}
\hline 0.3 & 0.3 & 0.5 & 0.74 & 0.98 & 1.04 & 1 & 1.2 & 1.1 & 0.91 & 0.69 & 0.74 \\
\hline
\end{tabular}

at medium WS, while Pitch deloading secures higher support but is more viable to WS fluctuations. The impact of $T_{f}$ width is reasonable as reflected by comparing Base case to Case 2, where extending $T_{f}$ increased incomes, mainly of Accelerative deloading and Pitch deloading. Increasing $\mathrm{T}_{\mathrm{f}}$ also expands the evaluation period such that WTG has longer interval to improve its performance, as PF is the average of the integral of compliance as in (9). Moving $T_{f}$ interval to include frequency nadir has a moderate benefit for Accelerative deloading since the provided support is high enough to comply with the requirements during the worst period of the event.

WS variability improves the incomes of Accelerative deloading and Pitch deloading, but it has limited impact on KE extraction method as observed when comparing Base case to Case 5. KE extraction achieves the highest cumulative payments in Cases 6 and 7, although the PFs of these two cases are slightly worse compared to other methods. As an illustration, the $\mathrm{PF}$ is the deduction ratio of the overall payment in these two cases, where KE extraction method provides more support power and energy, hence the payment does not rely only on PF but also the amount of support. In addition, this payment is cumulative for the worst 12 events of the year. Pitch deloading achieved its lowest income in Case 3 when $T_{f}$ is shifted to include frequency nadir, where the available support is insufficient to cover such tough frequency excursion.

To give more insights on these payments the average support power for the 12 events are obtained and displayed in Figure 15. The payments and average support power have the same pattern, although the cumulative payment relies on both the supplied power and energy at each event. This ensures that power payment has the main share in GP compared to energy due to the very short support duration, curtailing the provided amount of support energy.

\section{CONCLUSIONS}

Provision of frequency support by wind power is a critical challenge to enable high penetration levels of wind energy to future power systems. The verification and evaluation of WTGs/WPPs performance as providers of such ancillary service are essential. This paper offers a detailed payment and penalizing scheme that relies on the actual performance of wind energy frequency support and the corresponding system frequency data. This scheme considers the applied grid code, and aims not to compromise power system security; mainly it does not treat the amount of support in a proportional relation to compensatory payments, where excess and lack of support power is penalized. The performance of this payment and penalizing scheme is tested under a broad comparison of eight case studies that exploit the impact of wind speed, parameters of frequency support controls, and key factors of the scheme.

Results show the merit of Accelerative deloading, meanwhile KE extraction is barely achieving incomes. However, the latter method does not waste any energy at normal operation, as it does not deload wind power. The low income reflects potential threats to power system stability, as it emphasizes high non-compliance with grid codes and biddings. The selection of evaluation time interval is a critical challenge. The common approach is that, the wind turbine provides support as soon as frequency departs the deadband, because it is hard to predict exactly when the frequency nadir will occur, but it can be safer to make the evaluation interval include the frequency nadir. However, this can be beyond the capabilities of wind power plants due to wind speed variability, mainly that frequency can stay outside the safe deadband for a few minutes.

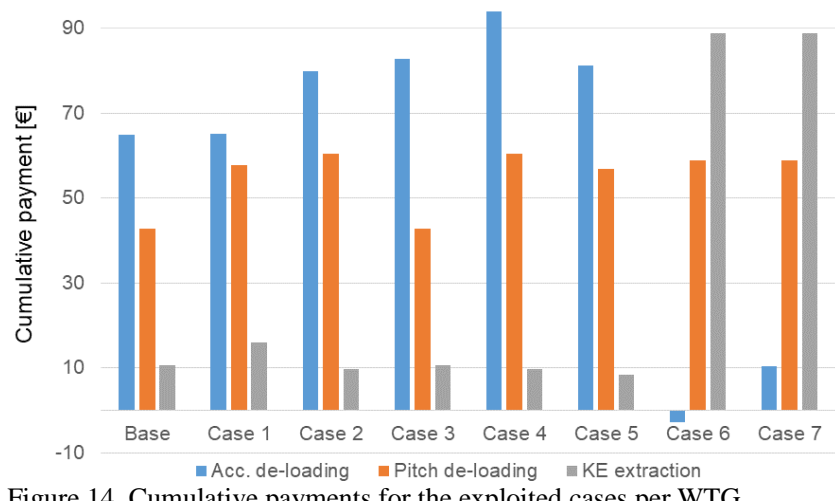

Figure 14. Cumulative payments for the exploited cases per WTG. 


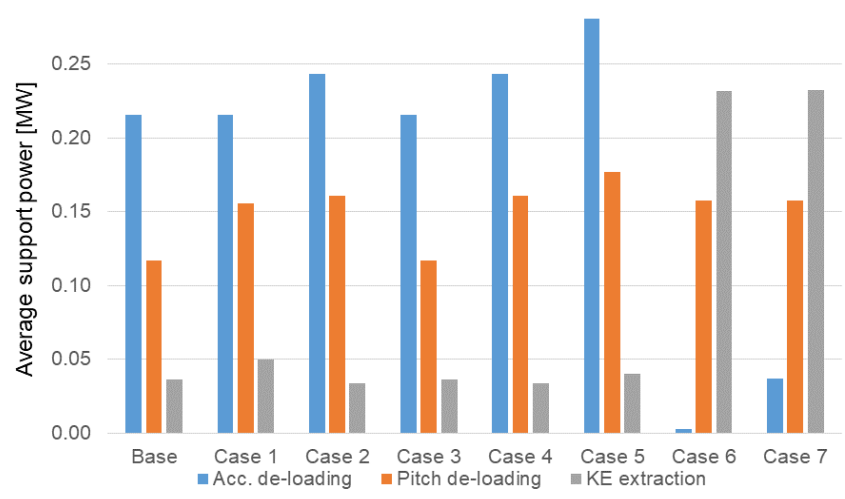

Figure 15. Average support across the 12 events in each case.

TABLE VII. IMPACTS OF KEY COMPONENTS OF SUPPORT PROCESS

\begin{tabular}{|c|c|c|c|}
\hline Parameter & Managed by & Impacts & Mainly relies on \\
\hline Support concept & \multirow[t]{2}{*}{$\begin{array}{c}\text { WPP } \\
\text { operators }\end{array}$} & \multirow{2}{*}{$\begin{array}{c}\text { Bids, } \Delta \mathrm{P}_{5} \\
\Delta \mathrm{P}_{30}, \Delta \mathrm{P}_{\mathrm{a}} \\
\mathrm{PF}, \mathrm{NP}\end{array}$} & $\begin{array}{l}\text { WTG technology, } \\
\text { dominant WS } \\
\text { conditions }\end{array}$ \\
\hline $\mathrm{f}^{\mathrm{m}}{ }_{\mathrm{d}}$ and $\mathrm{f}_{\text {low }}$ & & & Grid code \\
\hline $\mathrm{T}_{\mathrm{f}}$ and compliance zones & \multirow[b]{2}{*}{ SOs } & \multirow{2}{*}{$\begin{array}{c}\mathrm{PF}, \mathrm{NP}, \delta_{G C}, \\
\delta_{\Delta P}\end{array}$} & $\begin{array}{c}\text { Grid code, power } \\
\text { system nature }\end{array}$ \\
\hline Synthetic response & & & $\begin{array}{l}\text { Grid code, evaluated } \\
\text { frequency event }\end{array}$ \\
\hline
\end{tabular}

The barriers against actual application of the proposed method are the commitment of involved parties, i.e. system operators, wind power plants' operators, and market regulators, the implementation approach. For example, it is preferable to send the system operators evaluation to wind power plants sooner, in order to minimize bad practices of wind power plants, and mitigate the possibility of penalizing them in shorter terms. Moreover, data collection and precision are critical, as system operators need access to the chronological data of wind power generation in an adequate resolution. This can be applied to either a single WTG or the whole WPP, where the latter is easier due to reduced volume of data, as system operators look at power output at the point of connection of the wind power plant. The data can be updated at the end of each window, hence the system operators can apply the method offline. System operators accumulate net payments until a certain time point (e.g. weekly liquidation) that is informed to market regulators.

\section{REFERENCES}

[1] Directorate-General for Research and Innovation (European Commission), "The Strategic Energy Technology (SET) Plan," 2017.

[2] European Network of Transmission System Operators for Electricity, "Network Code for Requirements for Grid Connection Applicable to all Generators," ed: European Network of Transmission System Operators for Electricity, March 2013.

[3] H. Holttinen, A. Ivanova, and J. L. Dominguez, "Wind power in markets for frequency support services," in Proc. IEEE 13th Int. Conf. EEM, 2016.

[4] J. Morren, S. W. H. de Haan, W. L. Kling, and J. A. Ferreira, "Wind turbines emulating inertia and supporting primary frequency control," IEEE Trans. on Power Systems, vol. 21, no. 1, pp. 433-434, 2006.

[5] A. B. Attya, J. L. Dominguez-Garcia, and O. Anaya-Lara, "A review on frequency support provision by wind power plants: Current and future challenges," Renewable and Sustainable Energy Reviews, vol. 81, pp. 2071-2087, 2018.

[6] W. Ye, G. Delille, H. Bayem, X. Guillaud, and B. Francois, "High Wind Power Penetration in Isolated Power Systems - Assessment of Wind Inertial and Primary Frequency Responses," IEEE Trans. on Power Systems, vol. 28, no. 3, pp. 2412-2420, 2013.
[7] A. B. T. Attya and T. Hartkopf, "Control and quantification of kinetic energy released by wind farms during power system frequency drops," IET Renewable Power Generation, vol. 7, no. 3, pp. 210-224, 2013.

[8] M. Deepak, R. J. Abraham, F. M. Gonzalez-Longatt, et al, "A novel approach to frequency support in a wind integrated power system," Renewable Energy, vol. 108, pp. 194-206, 2017.

[9] J. Lee, E. Muljadi, P. Sorensen, and Y. C. Kang, "Releasable Kinetic Energy-Based Inertial Control of a DFIG Wind Power Plant," IEEE Trans. on Sustainable Energy, vol. 7, no. 1, pp. 279-288, 2016.

[10] R. J. Nelson, "Frequency-responsive wind turbine output control," ed: Google Patents, 2012.

[11] I. D. Margaris, S. A. Papathanassiou, N. D. Hatziargyriou, A. D. Hansen, and P. Sorensen, "Frequency Control in Autonomous Power Systems With High Wind Power Penetration," IEEE Trans. on Sustainable Energy, vol. 3, no. 2, pp. 189-199, 2012.

[12] F. Hafiz and A. Abdennour, "Optimal use of kinetic energy for the inertial support from variable speed wind turbines," Renewable Energy, vol. 80, pp. 629-643, 2015.

[13] J. Tan and Y. Zhang, "Coordinated Control Strategy of a Battery Energy Storage System to Support a Wind Power Plant Providing MultiTimescale Frequency Ancillary Services," IEEE Trans. on Sustainable Energy, vol. 8, no. 3, pp. 1140 - 1153, 2017.

[14] A. B. Attya, O. Anaya-Lara, and W. E. Leithead, "Novel metrics to quantify the impacts of frequency support provision methods by wind power," in Proc. IEEE ISGT-Europe, 2016, pp. 1-6.

[15] Australian Energy Market Commission (AEMC), "Template for Generator Compliance Programs Review 2015," Sydney, 2015.

[16] (2015). Procurement of Control Power and Energy in Germany. Available: http://www.amprion.net/en/control-energy

[17] EirGrid, "EirGrid Grid Code, Version 6.0," Ireland, 2015, Available: http://www.eirgridgroup.com/sitefiles/library/EirGrid/GridCodeVersion6.pdf.

[18] Energinet.dk, "Technical regulation 3.2.5 for wind power plants with a power output above $11 \mathrm{~kW}$," Energinet.dk, Copenhagen2015, Available: http://www.energinet.dk/EN/El/Forskrifter/Technicalregulations/Sider/Regulations-for-gridconnection.aspx.

[19] ENTSO-E, WGAS, "Survey on Ancillary services procurement, Balancing market design," Brussels, 2018

[20] National Grid Electricity Transmission plc, “The Grid Code Issue 5,” UK, Available:

https://www.nationalgrideso.com/sites/eso/files/documents/00_FULL_G RID_CODE_I5R27.pdf.

[21] T. Ackermann et al., "Scaling up variable renewable power: The role of grid codes," IRENA, 2016.

[22] KEMA, "System services international review - Market Update," EirGrid, 2011, Available: http://www.eirgridgroup.com/sitefiles/library/EirGrid/System-Services-International-Review-KEMA.pdf.

[23] M. Tsili and S. Papathanassiou, "A review of grid code technical requirements for wind farms," IET Renewable power generation, vol. 3, no. 3, pp. 308-332, 2009.

[24] Elia, "The primary reserve: a solution for stabilising the frequency in the European interconnected system," Available: http://www.elia.be/en/products-andservices/ /media/files/Elia/Productsand-services/ProductSheets/SOndersteuningnet/S1_F_RES_PRIMAIRE.pdf.

[25] National Grid. Network frequency response - 2016 [Online]. Available: https://www.nationalgrid.com/uk/electricity/balancingservices/frequency-response-services/firm-frequency-response

[26] The Commission for Energy Regulation, "Rate of Change of Frequency (RoCoF) Modification to the Grid Code," Republic of Ireland2014.

[27] T. K. Vrana, L. Trilla, and A. Attya, "Development of a generic future grid code regarding wind power in Europe," presented at the 16th Wind Integration Workshop, $2017 . \quad$ Available: https://strathprints.strath.ac.uk/62533/

[28] A. B. Attya, J. L. Dominguez-Garcia, and O. Anaya-Lara, "Estimation of frequency support market indices using Monte Carlo simulation for wind power generation," in Proc. 7th IEEE ISGT-Europe, Turin, 2017.

[29] Aeolus FP7. Simplified NREL5MW turbine for Simulink [Online]. Available: http://www.ict-aeolus.eu/SimWindFarm/index.html

[30] A. B. T. Attya and J. L. Dominguez-García, "Insights on the Provision of Frequency Support by Wind Power and the Impact on Energy Systems," IEEE Trans. on Sustainable Energy, vol. 9, no. 2, pp. 719-728, 2018.

[31] J. Yan, Y. Liu, S. Han, Y. Wang, and S. Feng, "Reviews on uncertainty analysis of wind power forecasting," Renewable and Sustainable Energy Reviews, vol. 52, pp. 1322-1330, 2015. 